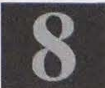

\title{
¿Qué importancia le asigna a una estrategia social en un contexto
} amplio de desarrollo económico?

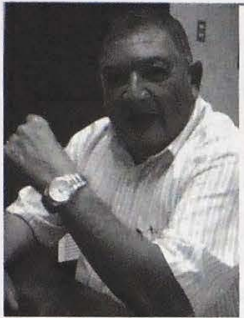

Jorge Barraza lbarra, UTEC
El concepto de desarrollo económico, definido y aceptado teóricamente, significa en pocas palabras, un proceso de crecimiento de la economía, pero aunado a una mejoría en el bienestar de la población. No se puede hablar de desarrollo económico, si éste no lleva aparejado un esfuerzo de progreso social, que comprenda los más amplios sectores de la población. Aunque el espacio político particular, de cada país, define la naturaleza de su estrategia de desarrollo con respecto a sus propias realidades, no es posible ignorar, hoy en día, que el atraso social limita muy seriamente las potencialidades del crecimiento. Cada familia pobre, que no accede a la canasta básica, que no puede proveer del estudio necesario para sus hijos, que carece de las condiciones de una vida digna, en lugar de ser un motor para el crecimiento es un lastre. Muchas veces, no entiendo porqué, no se quiere aceptar que la pobreza es una limitante para el crecimiento de una economía de mercado, que se fortalece con una mayor demanda y una más alta capacidad de compra.

La respuesta es muy sencilla, sin una estrategia social que incorpore al proceso productivo a una mayor cantidad de familias trabajadoras, no hay desarrollo posible.

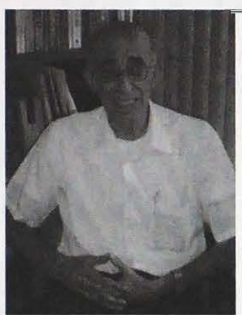

Javier lblsate, UCA
Simplemente, no puede haber "desarrollo económico" sin una estrategia social. A veces hablamos de "economía social de mercado" y sería bueno repasar cómo la entendieron los "ordoliberales" de Alemania occidental. También A. Giddens publicó "La Tercera Vía: la renovación de la socialdemocracia" (Taurus, Madrid, 1999) lo que quiere decir que incluso en Europa se están buscando modelos sociales, porque la globalización desnuda es inhumana. Por ello, es importante seguir la discusióny los programas presentados en los Foros Sociales de Porto Alegre y este año en Bombai, India...

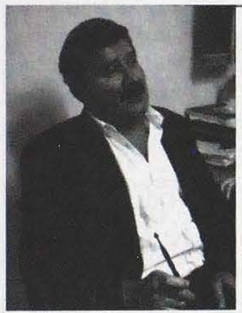

Roberto Rublo, FUNDE
Los estilos de crecimiento queha tenido este país no han bajado, en buena parte, a amplios segmentos de la población, esto tiene que ver con una política social. Que es algo que no puede verse separado de la política económica, sino que debe ser parte.

Existen muchas experiencias empíricas, en otros países, que indican la relación entre crecimiento y concentración o desigualdad: a mayor desigualdad el crecimiento es menor. Países con estructuras productivas más equitativas donde el producto está mejor repartido han crecido más y sostenidamente. Debemos buscar mecanismos que permitan democratizar la propiedad, combatir monopolios, fomentar la competencia, asegurar mecanismos para que los sectores de la pequeñay mediana empresa sean previligiados en el reparto de las oportunidades, crear mecanismos de protección a los débiles, a los pequeños y medianos ante las amenazas de distinto tipo.

Estas son algunas de las cosas de política social que están estrechamente vinculadas a la política económica. La política social tiene que ver con la desigualdad, con dar mayor oportunidad a los pequeños y medianos, para que puedan tener ingresos, y mejores servicios básicos públicos como: agua, electricidad. Creo que la política social tiene un componente amarrado a la parte económica, que tiene que ver con el empleo, con la equidad. Eso es social. 


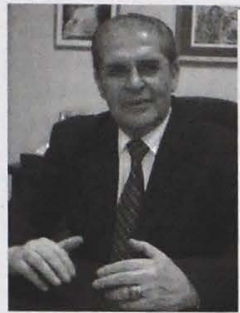

Rafael Rodriguez Loucel, UTEC
En pocas palabras, sin beneficio social generalizado y una mejora de la calidad de vida palpable, se puede hablar de cualquier cosa, menos de desarrollo. El beneficio ùlterior del mejoramiento económico es el beneficio social; esa es la razón de ser de pretender un desarrollo económico, en compañía con la conservación y mejora del medio ambiente para lograr la tríada que se ha venido conociendo como desarrollo sostenible. En tal sentido, no sólo el gobierno es el responsable de asegurar a todo ciudadano una mejor calidad de vida, sino también la clase empresarial debe de asumir una responsabilidad social.

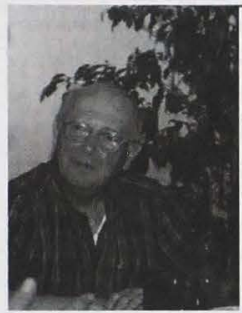

Héctor Dada Hirezl, Diputado CDU
Parecesuperada la tesis de que la mejor política social es una economía en crecimiento, y se ha pasado (o retornado) a la visión de que una sana y eficaz política social es el sustento de una buena política de desarrollo. Más bien, son dos aspectos de la misma política que interactúan entre sí. La falta de salud y educación, por ejemplo, conspiran contra la eficiencia de la economía y la capacidad de competir en sectores con requerimiento de procesos técnicamente complejos. La falta de atención adecuada a las condiciones sociales de capas poblacionales puede conducir a problemas de gobernabilidad que atentan contra el desarrollo. La progresiva diferenciación de las condiciones de vida de sectores ciudadanos contribuye a la generación de inestabilidades negativas para el desarrollo.

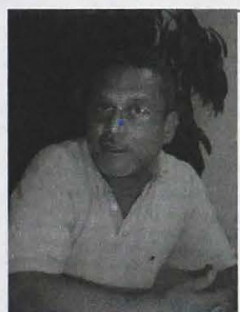

Carlos Briones, FLACSO
Las políticas sociales tienen dos grandes impactos, en el bienestar de la población a los que son dirigidas, y en las oportunidades que genera en la acumulación de capital humano para los diferentes grupos sociales. El capical humano son las competencias, y estas se derivan finndamentalmente del nivel de escolaridad y las condiciones de salud. La política social debe estrarégicamente buscar y mejorar las condiciones de creación de capital humano y medir la calidad de ese capiral humano con que cuenta.

Además, debe ser una política social donde los limitados recursos fiscales, deben orientarse hacia aquellos sectores más vulnerables y hacia los problemas más estratégicos que van a limitar las oportunidades de estos sectores en el presente y en el futuro.

Por ejemplo, debería apuntar a tratar de reducir la desnutrición infantil, tratar de mejorar las condiciones de salud preventiva, porque la desnutrición entre los cero a cinco años, es un momento clave, si el menor se atrasa en ese periodoserá difícil lograr que tenga al cos niveles de rendimiento como adulto. El gobierno debetratar de crear una política social integrada en la que participe tanto la sociedad civil y los sectores empresariales privados, porque somos un país de bajo desarrollo y con recursos fiscales bastante limitados, por lo que es necesario delimitar prioridades económicas y sociales. 